\title{
THE APPEARANCE OF PLACE IDENTITY IN THE URBAN LANDSCAPE BY USING THE NATURAL FACTORS (A CASE STUDY OF YASOUJ)
}

\author{
Mehrdad Karimi MOSHAVER ${ }^{a}$, Farshad NEGINTAJI ${ }^{b}$, Hamid Reza ZERAATPISHEH $^{c}$ \\ Institute of Architecture of Bou Ali Sina University, Janbazan Blvd, 1, LT-65176568978 Hamedan, Iran \\ E-mails: ${ }^{a}$ kmoshaver@yahoo.com; bfarshad.negintaji@yahoo.com; \\ chamidrezazeraatpisheh@yahoo.com (correspondingauthor)
}

Received 22 November 2014; accepted 04 June 2015

\begin{abstract}
This study has examined the effects of natural factors (urban landscape) on the place identity. In order to perform this, the place identity has been measured and also its relationship with the components of natural factors, absolute elements, living elements and natural elements have been measured. The study is descriptive and the statistical population has been Yasouj which is a city in Iran. To analyze the data the SPSS software has been used. The results have been investigated in two levels of descriptive and inferential statistics. In the inferential statistics, Pearson correlation coefficient has been used to evaluate the research hypotheses. In this study, the variable of place identity is in high level and the natural factors are also in high level which these results indicate a positive relationship between place identity and natural factors. The results indicate that natural factors have significant role on Yasouj landscape and also increase the place identity. It can be inferred that the development of natural factors and reaching it to the qualified level will develop the place identity.
\end{abstract}

Keywords: identity, place identity, landscape, urban landscape, landscaping, nature.

\section{Introduction}

Natural factors played an essential role in ancient Iran which had a significant impact on Iranian identity. Unfortunately, the disregard and destruction of nature can be observed in the modern age that this problem lead to change the identity in the cities of Iran. The purpose of this paper is to consider the impact of natural factors on the identity of place and with respect to the natural values, nature-friendly cities to be formed.

Human is the only creature among all creatures that has the ability to create new identity for himself or herself and his or her artifacts. In order to create new identities inspired by the elements and natural phenomena for their artifacts, which the city is the largest human construction, human creates new identity appropriate to the material and spiritual needs at different times. In fact, the authentication in urbanistics landscape makes future generations benefit from the familiar atmospheres. Since one of the key factors for human authentication is the relationship between his/her constructions and cultural, natural, physical as well as environmental components, any change in these components will also be a change in the identity. With this interpretation, the concept of identity in the urban landscape is caused by the anatomy, collective memory and culture of the city. Although the passage of time, increasingly cause collective memory and culture of the city. Place as having identity and abstract meanings by date and definition of location, often means draw a border around and the separation of inside and outside. Place has three components of physical environment, surrounding activities and perceptional meanings that is mixed with understanding of the audience.

Physical environment plays an important role in defining the place so that it uses the length, width and height for the recognition and definition appropriate to the physical place. The surrounding activities of audiences when experiencing space in perception of place have perceptional effects.

We define place meanings by the use of our memories and past experiences. Place appears as the intersection points, local and global integration, creates a global sense of the world around; which is not static, continually generated and again produced, in interaction with their surrounding environment it may achieve new meanings 
over a period of time. An architect of a building, has a certain idea and in order to be able to portray the idea $\mathrm{s} /$ he needs to create space, and this is the space which determines which wall needs what type of materials and what color appears where in the building. Maybe a lot of people have this misconception that architectural space consisted of walls, columns and ceilings that were enclosed. Although this is a completely false impression for the architectural space, because, as it was mentioned, this is the nature of space that determines what element places where in the building (Atashinbar 2009).

The case study is the city of Yasouj in Iran in the foothill of the Zagros mountains and is located in the south-western Iran. Figure 1 shows the nature of Yasouj national park, Figure 2 illustrates the current situation of Yasouj and Figure 3, 4, 5 present Yasouj natural views. Yasouj cold and mountainous climate with slopes less than $20 \%$ from north to south are

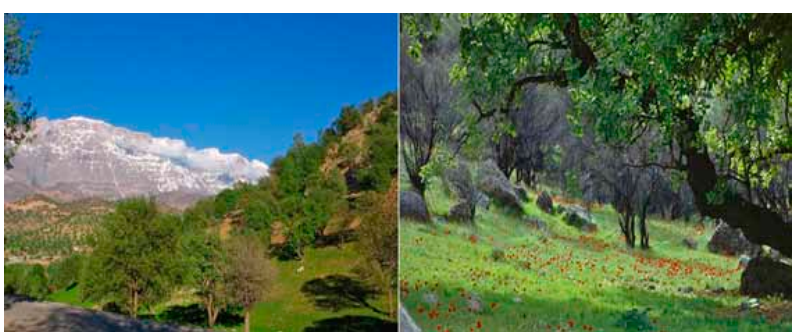

Fig. 1. Yasouj nature (photo by the authors)

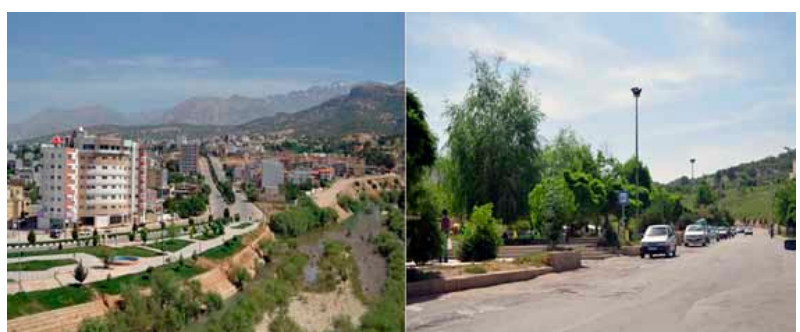

Fig. 2. Yasouj city (photo by the authors)

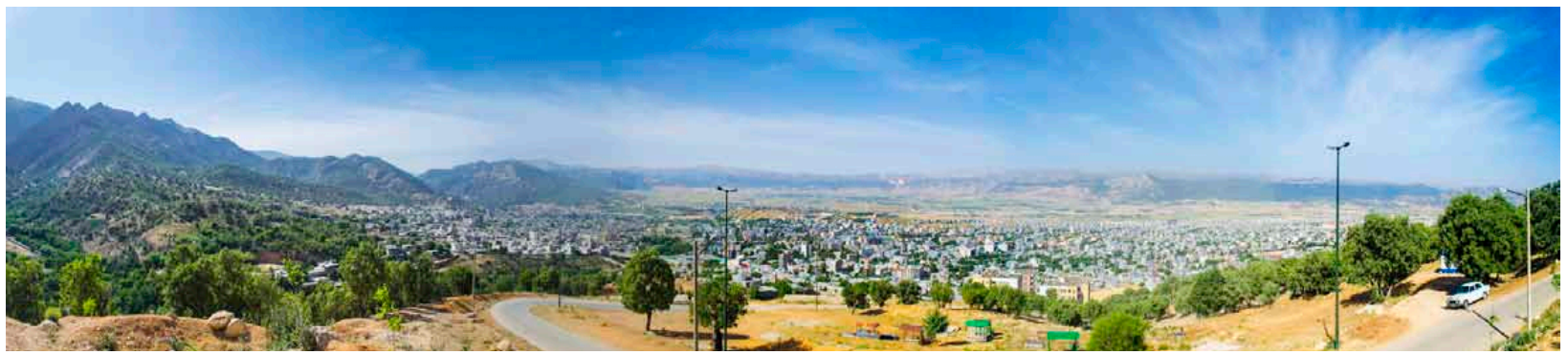

Fig. 3. Northern view of Yasouj panorama (photo by the authors)

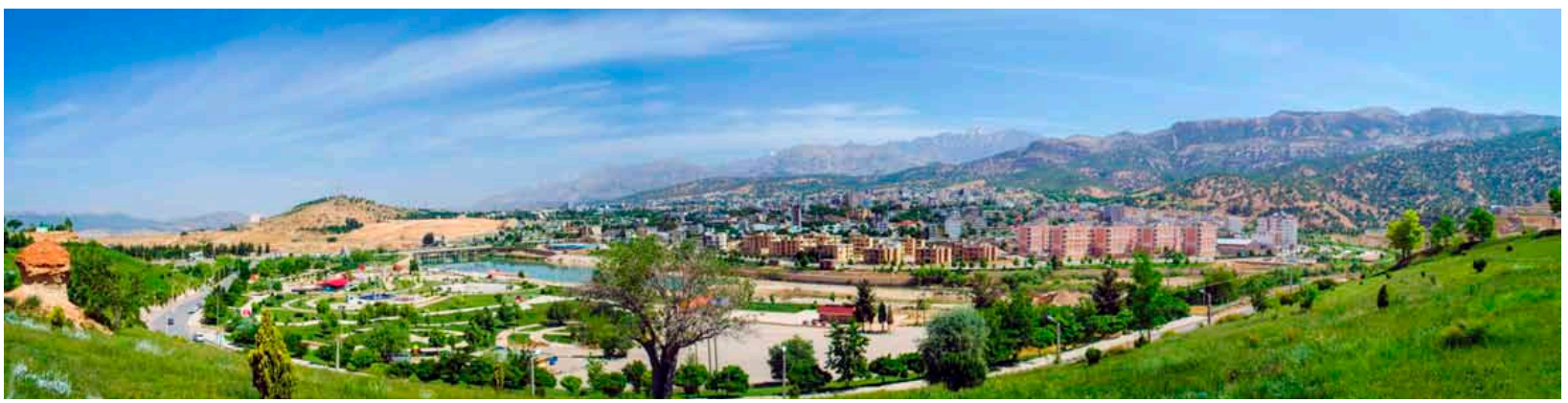

Fig. 4. Western view of Yasouj panorama (photo by the authors)

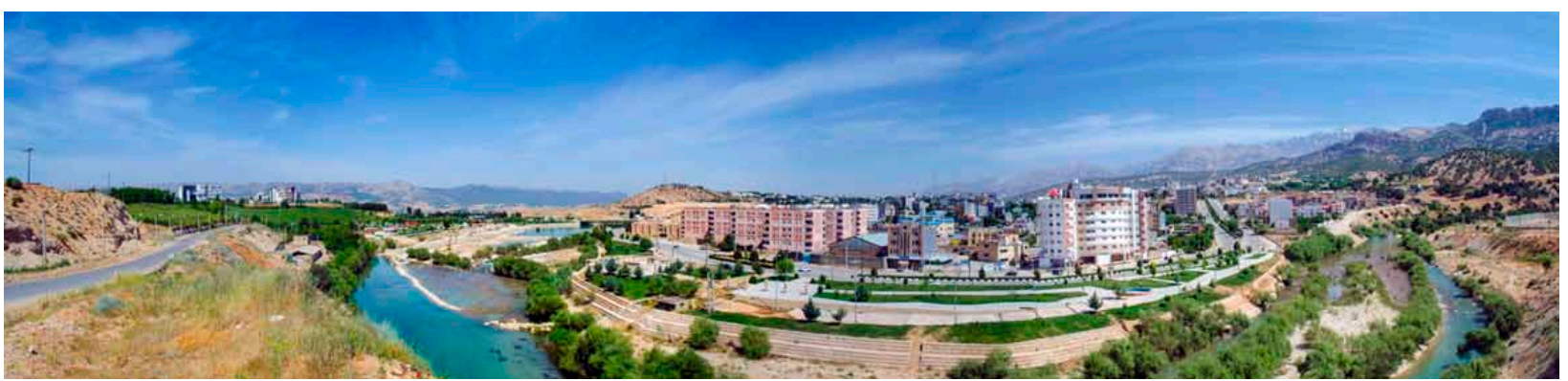

Fig. 5. Southern view of Yasouj panorama (photo by the authors) 
characteristic of this city. The city has mountainous and wilderness nature and thick forests of oak with more than $750 \mathrm{~mm}$ of rainfall per year (Portal of Meteorological Organization of Iran 2015).

\section{Literature review}

\section{Identity}

Stedman about the relationship between place and identity and the impacts of environment on them state that place as a set has the potential to contribute to develop the process in which people's sense of place, belonging and identity and preserve them. Place is at the center of the world or social world. When humans interact with its environment, places have been formed or made from the spaces (Stedman 2002).

Regarding the elements of identity Noghrehkar believes: "the constituent elements of identity include the characteristics and natural elements (natural environment), characteristics and individual elements which include gender, age, occupation, characteristics and human elements (human environment) which include race, family, language, history, civilization, culture, tradition and religion" (Noghrekar 2003). In this paper natural factors have been investigated as the constituent elements of identity.

About individual's formation of identity (character) there are three perspectives (Fig. 6):

1. Identity is the product of inner instinctive aspects of human being. Psychologists who are concerned on their ego (self) are followers of this theory. Among theorists, Freud poses the discussion of adaptation of me, or premier me with the existing and new environments and what the atmosphere is going to be. Mary thinks that external factors or environment affect on character and behavior of the person, or external factors, although she proposes: "Environment or external factors make only human activities to meet the needs easy or difficult" (Siyasi 2001: 40). She has emphasized on the influencing inner aspects of personality. So that environment, elements, objects as well as place can be understood as there are and so are effective in the behavior of a person

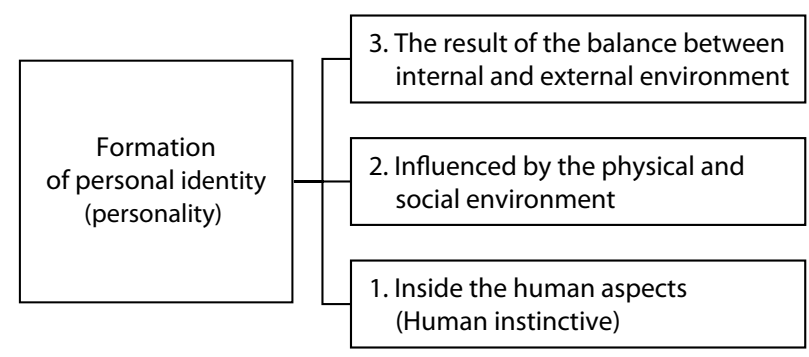

Fig. 6. Formation of personal identity, personality (Siyasi 2001) as she/he observes them. Thus changes are carried out in self than the outside environment. Jung points out that the balance between introversion and extraversion cause dehiscence of disconnection with the past and can cause the character to become rootless. Human cites that such discomforts have been created in modern civilization. A kind of "alienation" occurs for a man when the roots are disconnected (Jung 1999: 82). He emphasizes on signal codes, which are internal - external matters to grow personality, so that one may conclude that places are codes that the more human develops the more attention will they receive. If a person's incentive, need and mental imagination in the external and environmental conditions that places him/her in connection with them, has no consistency or balance or would be in conflict and confrontation, tries to adapt to the environment and new elements, but even if this is not fulfilled, she/he would be in internal inevitability and has no alternative but to admit personality disorders and this results in the personality destruction of individual and social environment and so his or her living place.

\section{Identity is the product of physical and social envir-} onment. Sociologists such as Erich Froam believe that the differences between human and animal include not being in the captivity of instincts, having the knowledge of self, being aware of the destiny and having the specific needs. Human's specific needs from his/her point of view are the need for transcendence, bond and relative, the need to be similar and the need to refer to the original. These needs have not been influenced by society but how to manifest is dependent on the society. Unlike Freud, he thinks that characters does not make society, although it is the society that makes the characters. With regard to making character, Sulivan says: "Human personality emerges when connecting to a person or other persons show behavior" (Mehrara 1995: 196). In the second approach, changing the environment and reaching it a qualified level of personality or identity of the individual and society have been considered. Thus the external environment is crucial. That is attitudes, motivations, perceptions, and in general personality or identity without having the society will not be developed.

3. Identity is the result of the balance between internal and external environment. This attitude of personality is the result of the interaction of body and the physical and social environment. This view is in the thought of those like Adler, Horney's and Murphy. Adler describes man as a social creature and articulates social desirability as motivation for his/her behaviour. He considers self-consciousness as the center of personality: "Man is self-conscious and all the attention refers to self-consciousness. She/he is aware of his/ her shortcomings and failures and the target that $\mathrm{s} / \mathrm{he}$ 
pursues" (Siyasi 2001: 93). Horney believes that man's relationship with society on one hand and the culture of society on the other hand and type of education of a person, gives him/her a relatively stable behaviour which distinguishes him/her from other people (Siyasi 2001: 94). Formation and evolution of personality is quite eclectic from the Gardner Murphy's perspective. According to him, man not only is a biological but also a social phenomenon, thus, in discussing the formation and evolution of personality, environment and organism should not be placed against each other, since they have complete continuity and interaction (Siyasi 2001: 86). From this perspective, place causes possibilities and limitations so that behaviors that have biological basis are formed and manifested. In all these theories, man and the universe have been viewed as two separate things from each other, and each one is the basis to form the other. In these perspectives, while accepting the mind and the universe as two independent things and even against each other, there is a dispute whether mind makes the outside world or the outside world makes mind.

\section{Identity in theories of urban planning and architecture}

Identity can be identified and assessed in the field of Architecture and Urban Planning in social-cultural and psychological context. Lewis Mumford by protesting to modern cities states: "Buildings and new neighborhoods have rigid and constrained order and have no distinction that the man himself caused it." He believes that a clear image of the environment, is a positive factor in individual's self-recognition and environment and helps individual to grow and states the role of an alive and continuous anatomy: "An alive anatomical framework is compeletely continuous and is able to create a consistent image and plays a social role. This framework can be primary helpful symbols and collective commemorations which are used in communication between the groups. In addition to that a favorable image of environment gives the person a profound feeling of security. After this, one can establish a harmonious relationship with the outside world. This private and legible environment not only increases security but also increases the depth and intensity of human experience" (Shuai 1997: 388).

\section{Place identity}

According to Morley and Robins, whether in terms of inclusion and exclusion, in terms of unique symbolic value, whether national or more broadly cultural, place identity, as it bears on landscape, is simply an idea with a history, a geography, an imagery and a vocabulary or depends on such in order to assume reality and presence in and for a human group of reference. What renders a landscape distinctive as a place is primarily its distinctive geography (Morley, Robins 1995: 45).

\section{Factors shaping the identity of place}

Way in which place has been related to identity is through the term place identity, a construct promoted by Proshansky et al. $(1983,1987)$ which calls for a more radical re-evaluation of construct of identity. He proposes that place identity that describes the person's socialization with the physical word. Since he takes a Meadian approach to the self there is an assumption that the processes operating between place and identity are the same as between groups and identity. Rochberg-Halton (1981) gives a good account of how objects and places can become part of the generalized other and thereby incorporated into the self-concept. However, it is never made clear by Proshansky what the relationship is between these two aspects of identity. Whilst it may be possible to discuss the relationship between the physical environment and identity without reference to a group, to have two forms of identity would focus discussion on whether or not identity was more 'social' or more 'place'. This would not seem to be useful in explanatory terms. In addition it contradicts environmental psychologists' transactional perspective on place (Sageart, Winkel 1990).

"We agree with Proshansky that there has been a neglect of the physical environment by self-theorists. We would, however suggest that rather than there being a separate part of identity concerned with place, all aspects of identity will, to a greater or lesser extent, have place-related implications" (Twigger-Ross, Uzzell 1996: 206).

\section{Landscape}

The word landscape is the visible features of an area of land including elements, the physical form of land, waters form such as rivers, lakes, living entities, land cover including vegetation, made elements by humans such as usage, buildings, structures, temporary and transitory elements including lighting and weather conditions. The combination of these elements accompanying with the presence of humans often creates landscape that reflects a synthesis of human's life and place. Landscapes and their attributes and the quality of landscapes define the notion of a place, sense of one place which distinguishes it from other places. Seifoddini (2013: 3) in Appearance and configuration 


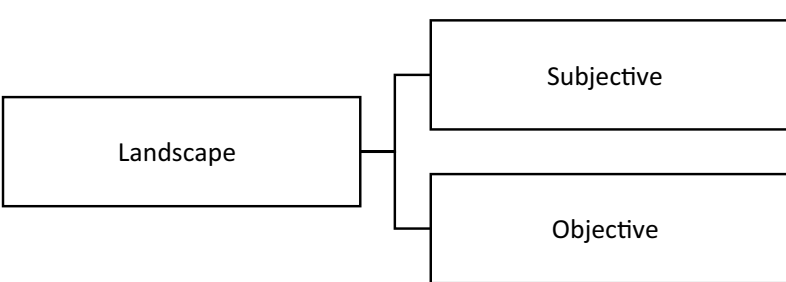

Fig. 7. Landscape (Turner 1996)

argues that the application of place is generally associated with specific moments. Entering into any place what is initially identified for the observer is the appearance and configuration of that place which depicts the general characteristics of that place to visitors. Turner (1996) in the book City as landscape, defines the term landscape as follows: "Considering the history of syntax, it is reasonable that term landscape (perspective) is applied to mean a certain view of the world (Fig. 7).

1. The physical aspect of landscape (perspective) will be determined by person's geographical situation.

2. Psychological aspect of landscape (perspective) will be defined by mental structures which interpreted through sensory (Turner 1996: 117).

From a geographical perspective, landscapes, as complex realities, exist in historical time, and thus, tend to exhibit special identifying features; they function "as systems of energy, material and information flows interwoven in real, perceived which are reflective of the basic organization of society and economy, and thus, they may be read rather like texts" (Meinig 1979). According to the Terkenli (2001: 206-207), sustainable, integrated landscape management, thus, now more urgently than ever before, needs to address, combine and connect a large number of diverse landscape functions, such as ecological stability, economic viability, expression of place identity, recreational activity, dynamics and so on.

Landscaping refers to any activity that changes the visible features of an area of the land (Seifoddini 2013: 6). Landscape elements include the following four factors (Fig. 8):

1. Living elements: Including ground vegetation cover, animals, or what is called the farming, this is the art of growing plants to create a beautiful environment within the landscape.

2. Natural elements: Forms of land surface, plains forms, highlands and water forms.

3. Human factors: Structures, buildings, fences or other material objects that have been created and installed by humans.

4. Absolute elements: Weather and light conditions.

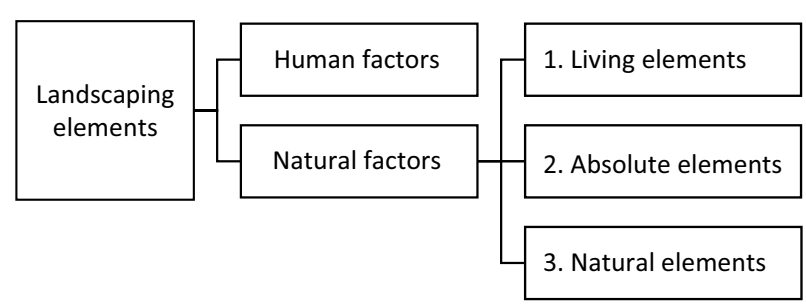

Fig. 8. Landscaping elements (Seifoddini 2013)

\section{Nature}

Nature has had an essential role in architecture and Iranian urbanism and been very important in the traditional ideoalogy and considered as a contributing factor to the metaphysics and the order of universe. In addition, the nature always has been considered as the most important model for Iran's traditional architects and urban planners. In Dehkhoda dictionary nature is described in this way: "It is the temperament that people have been created with it, body, water, soil, gem, temperament, essence, instinct, etc., and four elements (in Persian Charakhshj) are soil, water, wind and sun" (Fig. 9) (Dehkhoda 1999: 15381). Another Iranian philosopher, Ibn-e Sina has used the term nature as several meanings of which the most fundamental one is the force that causes to move elements (Nasr 1999: 331). These definitions show the significant role of natural elements to create a climate-oriented architecture and its role on the Iranian identity.

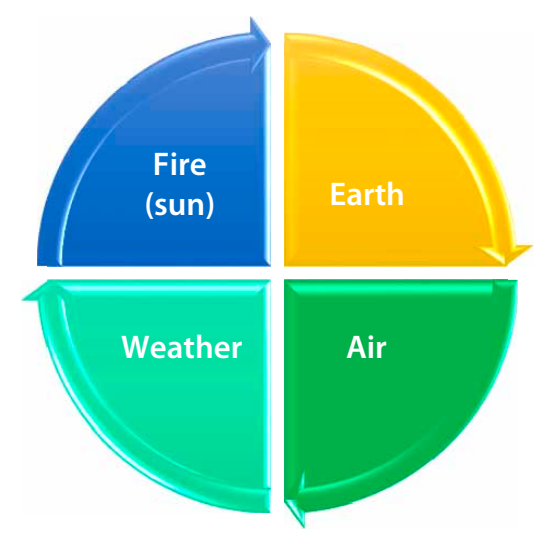

Fig. 9. Four natural elements from the Iranian viewpoint (Dehkhoda 1999)

\section{Materials and methods}

The purpose of this study is to investigate the role of natural factors on the identity. To perform this, a questionnaire has been provided which measures components of the natural factors, absolute, living and natural elements. Theoretical framework of landscape elements (natural elements) is created according to Seifoddini's (2013) Urban landscape book (Fig. 8). 


\section{Research questions:}

1. Is there a significant relationship between the place identity and natural factors?

2. Is there a significant relationship between the place identity and absolute elements?

3. Is there a significant relationship between the place identity and living elements?

4. Is there a significant relationship between the place identity and natural elements?

The current survey is descriptive. The assessment instrument is a questionnaire that has been made by the researcher and been based on the combined theoretical framework. The statistical population of this research has been the city of Yasouj. As the statistical sample haves been the central municipality districts 1, 2 and 3 (Fig. 10). The sample size has been obtained based on Cochran formula of 384 . Then 100 questionnaires were distributed among the people of these districts through the random cluster sampling method. SPSS software has been used to analyze the data and examined the results of both descriptive and inferential statistics. In inferential statistics, Pearson correlation coefficient has been used to examine the hypotheses. The validity of instrument for measuring research has been obtained through the content validity and face validity obtained by referring to the professors and receiving their consensus about the indices. Also the reliability of the measurement instrument was evaluated through item to item correlation. Cronbach's alpha ranging from zero to one is the reliability index of a measurement instrument. The alpha tends to be between zero and one. The more it tends to be near zero it indicates that the questions are inappropriate

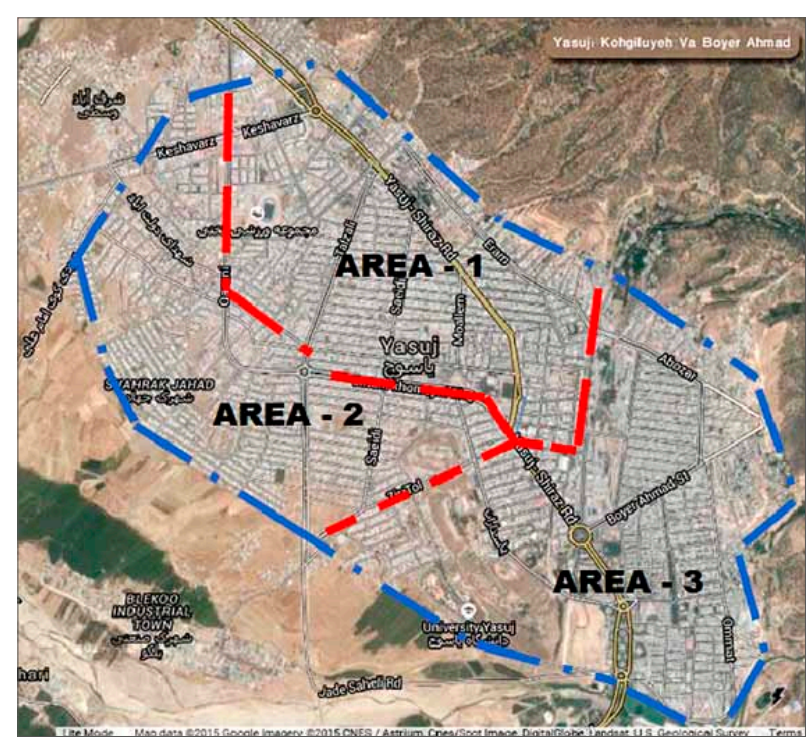

Fig. 10. Yasouj plan area (created by the authors) and the more it moves to 1 it shows that the questions are appropriate. Here the variable of place identity is 0.902 or at a high level and the natural factors is 0.768 or at the high level too.

\section{Research findings}

\section{Descriptive statistics}

According to descriptive statistics, research indicates that about $3.3 \%$ of the participants in this study were under 18 and approximately $73.3 \%$ of the respondents were between 18 and 28 years, $21.7 \%$ were between 29 and 39 years, and $1.7 \%$ were between 40 and 50 years. So the majority of participants in this study were between 18 and 28 years of age. With respect to gender, $54.4 \%$ of the respondents were male and $45.6 \%$ were female. Thus, most of the participants in this study were male. Level of education indicates that the majority of people in this study, approximately $65.3 \%$ have Bachelor's degree. The frequency relating to job shows that $38.2 \%$ were self-employed, $22.9 \%$ had governmental jobs, $1.4 \%$ were retired, $12.9 \%$ were housewives and $24.6 \%$ were unemployed. Therefore the majority of people in this research were self-employed. Approximately $45.5 \%$ of the participants in this study have lived in this area between 5 to 15 years.

\section{Results of the questionnaire}

Investigation of the place identity according to participants' opinion in Yasouj (Fig. 11).

The findings suggest that place identity of the participants in this research with 52.2 percent was at a high level and $40.3 \%$ in the average level and 7.5 percent was low. Therefore, the place identity of most residents in Yasouj was high.

Inferential statistics: In this section, according to research data, the relationship between the variables described above has been investigated. The study has 4 basic hypotheses (Table 1).

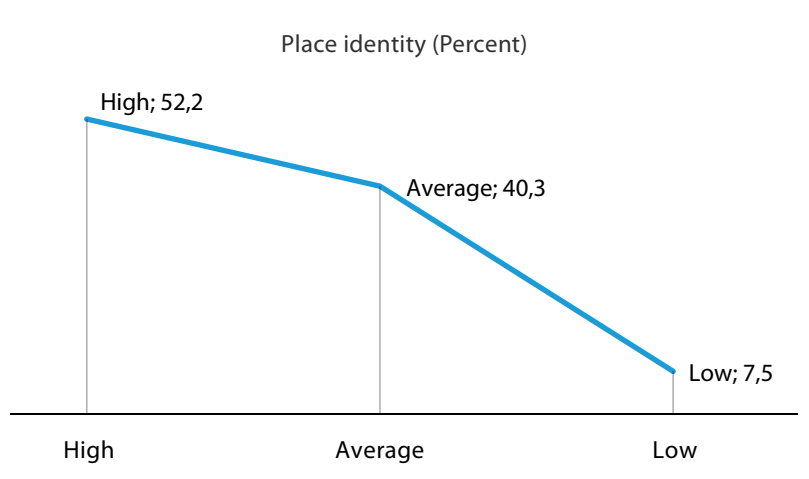

Fig. 11. Investigation of the place identity according to participants' opinion in Yasouj 
Table 1. The correlation coefficient of hypothesis 1

\begin{tabular}{|c|c|c|c|c|c|}
\hline & & 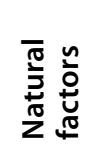 & 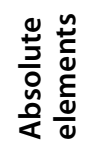 & 올 & 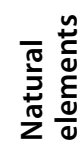 \\
\hline \multirow{2}{*}{ 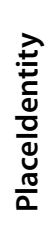 } & $\begin{array}{l}\text { Pearson } \\
\text { correlation } \\
\text { coefficient }\end{array}$ & 0.593 & 0.389 & 0.551 & 0.526 \\
\hline & $\begin{array}{l}\text { Significant } \\
\text { level }\end{array}$ & 0.000 & 0.002 & 0.000 & 0.023 \\
\hline
\end{tabular}

1. The relationship between place identity and natural factors, absolute elements, living elements, natural elements is significant.

To approve or reject these hypotheses temporarily, according to the measurement of variables, Pearson correlation coefficient has been selected as the statistical analysis. The correlation coefficient of these two variables is 0.593 which is in the average level and the significance level of 0.000 . Significant level is less than 0.05 and the hypothesis is approved at 95 percent level. Thus, there is a significant relationship in a positive direction between place identity and natural factors. Natural factors has three dimensions which include: climate, vegetation, and topography which these hypotheses are discussed below:

2. There is a significant relationship between place identity and absolute elements.

The correlation coefficient of place identity and absolute elements is 0.389 which is the average and the significance level of 0.002 . Significant level is less than 0.05 and the hypothesis is approved at 95 percent level. Thus, there is a significant relationship, in a positive direction between place identity and absolute elements.

3. There is a significant relationship between place identity and living elements.

The correlation coefficient of place identity and living elements is 0.551 which is the average and the significance level of 0.000 . Significant level is less than 0.05 and the hypothesis is approved at 95 percent level. Thus, there is a significant relationship, in a positive direction between place identity and living elements.

4. There is a significant relationship between place identity and natural elements.

The correlation coefficient of place identity and natural elements is 0.526 which is the average and the significance level of 0.000 . Significant level is less than 0.05 and the hypothesis is approved at 95 percent level. Thus, there is a significant relationship, in a positive direction between place identity and natural elements.
In general, it can be concluded that the maximum relationship at first is between place identity and natural elements due to having the more correlation coefficient and the second time is with living elements and the third time is with the absolute elements.

\section{Conclusions}

The results of the research indicate that natural factors play an important role on establishing the place identity of Yasouj as one of the newly built and foothills cities. So at first the maximum relationship is between the place identity and natural elements and in the second place is with the living elements and in the third place is with absolute elements. In order to develop the cities, natural factors should be considered as one of the most important items in the formation of urban design and prevent the destruction of nature and prevent converting it to the city that lacks identity.

\section{References}

Atashin Bar, M. 2009. Continuity of identity in urban view, Journal of Bagh-e Nazar 12: 45-56.

Dehkhoda, A. A. 1999. Dehkhoda dictionary. Iran, Tehran: Tehran University publication.

Jung, C. G. 1999. The psychology of unconsciousness. Translated by Mohammad Ali amiri. Tehran: New Thought.

Mehrara, A. 1995. The field of social psychology. Iran, Tehran: Mehrdad.

Meinig, D. Ed. 1979. The interpretation of ordinary landscapes: Geographical essays. Oxford University Press: Oxford.

Morley, D; Robins, K. 1995. Spaces of identity; global media. Electronic landscapes and cultural boundaries. London: Routledge. http://dx.doi.org/10.4324/9780203422977

Nasr, H. 1999. Islamic ideas about the nature. 4th ed. Tehran: Kharizmi.

Noghrekar, A. 2003. Identity and its crisis in contemporary architecture thought and urbanism. Tehran: Science and Technology Research Center.

Portal of Meteorological Organization of Iran. 2015. Yasouj weather station [online], [cited 20 April 2015]. Available from Internet: http://www.irimo.ir/far/services/climate

Proshansky, H. M.; Fabian, A. 1987. The development of place identity in the child, in C. S. Weinstein \& T. G. David (Eds.). Spaces for Children. New York: Plenum press.

Proshansky, H. M.; Fabian, A. K.; Kaminoff, R. 1983. Place identity: physical world socialisation of the self, Journal of Environmental Psychology 3: 57-83.

Rochberg-Halton, E. 1984. Object relations, role models and cultivatio of the self, Environment and Behaviour, 16: 335-368.

Sageart, S.; Winkel, G. 1990. Environmental psychology, Journal of Annual Review of Psychology 41: 441-477. http://dx.doi.org/10.1146/annurev.ps.41.020190.002301 
Seifoddini, F. 2013. Urban landscape. Tehran: Ayizh.

Shuai, F. 1997. City planning: imagination and reality. Translated by Mohsen Habibi. Tehran: Tehran University.

Siyasi, A. 2001. Theories of personality. Tehran: Tehran University.

Stedman, R. 2002. Toward a social psychology of place: Predictive behavior from place-based cognitions, attitudes, and identity, Journal of Environmental Behavior 34: 561-581. http://dx.doi.org/10.1177/0013916502034005001

Terkenli, T. S. 2001. Towards a theory of the landscape: the Aegean landscape as a cultural image, Journal of Landscape and Urban Planning 57(3-4): 197-208. http://dx.doi.org/10.1016/S0169-2046(01)00204-3

Turner, T. 1996. City as landscape: A post-postmodern view of design and planning. London: Taylor and Francis.

Twigger-Ross, C. L.; Uzzell, D. L. 1996. Place and identity processes, Journal of Environmental Psychology 16(3): 205-220. http://dx.doi.org/10.1006/jevp.1996.0017

\section{MEHRDAD KARIMI MOSHAVER}

Doctor of Architecture (2011). Institute of Architecture of Bou Ali Sina University, Janbazan Blvd, 1, LT-65176568978

Hamedan, Iran.E-mail: mkmoshaver@yahoo.com

Research interests: Urban landscape, cityscape, tall buildings.

\section{FARSHAD NEGINTAJI}

Student of Architecture (2014). Institute of Architecture of Bou Ali Sina University, Janbazan Blvd, 1, LT-65176568978 Hamedan, Iran. E-mail: farshad.negintaji@yahoo.com

Research interests: Place identity, landscape architecture, urban landscape, nature, cultural values.

\section{HAMID REZA ZERAATPISHEH}

Master of Architecture (2014). Institute of Architecture of Bou Ali Sina University, Janbazan Blvd, 1, LT-65176568978 Hamedan, Iran. E-mail: hamidrezazeraatpisheh@yahoo.com

Research interests: Sustainable development, creativity in architecture, sense of place, teaching architecture, place identity, landscape architecture, urban landscape, nature. 